\title{
SENSORY DEFICITS IN VISUAL AGNOSIA
}

\author{
BY \\ GEORGE ETTLINGER \\ From the Psychological Laboratory, Institute of Neurology, Queen Square, London*
}

In recent years, Bay $(1950,1953)$ has repeatedly claimed that the so-called " higher" perceptual disorders are secondary to sensory impairment, to general intellectual loss, to language disturbance, or to a combination of these three factors. He denies strongly that agnosia in its classical sense of a circumscribed defect of recognition, specific to a single sense modality, in reality exists. Bay maintains that abnormal alterations in visual function (pathologischer Funktionswandel) may be present in cases conventionally held to display symptoms of agnosia and may play an important role in the genesis of this disorder. Although these sensory deficits may escape detection on routine examination of the visual fields, it is argued that they are measurable by means of a special test of local adaptation. This test has been fully described by Bay $(1950,1953)$. His results indicate first, that alterations in adaptation rate are prominent in most patients with clinical signs of agnosia; and secondly that such visual deficits may occur in perimetrically normal areas of the visual field. In general, Bay reports that significant alterations in visual efficiency are present in all cases of "agnosia" in which there is neither disorder of language nor significant global deterioration.

These contentions have been critically examined at a symposium of German neurologists held in 1951. The consensus of opinion cannot be said to favour Bay's interpretation. Thus it was argued by both Jung (1951) and Scheller (1951) that visual impairment together with non-specific intellectual loss could hardly explain the diversity of visualagnosic syndromes and their relative specificity in terms of content (object agnosia, alexia, spatial agnosia, etc.). Faust $(1951,1955)$ has drawn a distinction between genuine and "pseudo-agnosic" symptoms; only the latter, he believes, are to be explained in terms of sensory loss in the manner proposed by Bay. It is also noteworthy that Russell (1951) has reported accelerated visual adaptation in the absence of visual agnosia; and Jaffe (1955)

\footnotetext{
- This report describes part of work which has been approved by
} London University for the award of the Ph.D. degree. has more recently described accelerated tactile adaptation without astereognosis. It would therefore appear that although sensory defects of the kind proposed by Bay may well occur in many cases of brain lesion, their relation to the classical agnosias is decidedly conjectural.

It should also be pointed out that there are certain methodological defects in the test procedure as reported by Bay (1953). In the first place, the effects of unilateral visual inattention (extinction) do not appear to have been given adequate consideration despite Bay's use of the condition of double simultaneous stimulation. In the second place, Bay's method of assessing the degree of adaptation defect in a particular patient by subtracting the value given from the mean value for an appropriate control group is far from satisfactory. It will readily be seen that this method would permit some " abnormality" to be recorded in about $50 \%$ of a healthy population. In the third place, Bay's method, which places stress on chromatic adaptation, is open to the objection that disturbances in colour recognition are commonly unrelated to other varieties of agnosia.

Despite these and other objections to Bay's methods, his views concerning agnosia have gained some measure of acceptance (cf. Critchley, 1953). Apart from purely theoretical issues, however, careful examination of more elementary visual processes in the manner suggested by Bay would appear a most valuable precaution in the analysis of cases presenting " higher" visual disabilities. An investigation has therefore been undertaken to assess the extent and significance of visual deficit in a series of 30 cases of brain lesion. These comprise (a) cases lacking both visual field defects (as conventionally ascertained) and signs of perceptual disorder (12 cases); (b) cases with field defects but without perceptual disorder (10 cases); (c) cases with field defects and various types of perceptual disorder (" agnosia ") (eight cases). These patients were tested on a variety of visual discrimination tasks using systematic psychophysical procedures, and the results evaluated with reference to the thresholds given by a large control group of healthy 
subjects. It is hoped first, to determine the incidence and magnitude of visual deficits in cases of cerebral lesion; and secondly, to assess their possible significance in relation to the "higher" disorders of visual perception.

\section{Apparatus}

An apparatus was constructed to enable discrimination on a variety of visual tests to be assessed quantitatively at representative points in the visual field. This apparatus allows all variables not directly related to the differences between the tests, e.g., background luminance, to be held constant.

An hemisphere made of plaster and of $1 \mathrm{~m}$. radius is set vertically in a room which can be fully screened from daylight (Fig. 1). The smooth inside of the hemisphere is coated with special matt white diffusing paint according to a formula developed by the G.E.C. Ltd. to reflect light of all wave lengths approximately equally. A large corrected field lens is mounted behind a circular aperture of $6.3 \mathrm{~cm}$. diameter let into the centre of the interior surface of the hemisphere. The interior is illuminated by two $4 \mathrm{ft}$. $40 \mathrm{w}$. " natural Osram " fluorescent tubes suspended vertically one to each side, at about $2 \frac{1}{2} \mathrm{ft}$. from the rim. These tubes are supplied with $230 \mathrm{v}$. A.C. from a constant voltage transformer. The luminance of the central part of the hemisphere is always maintained at a level of $34.7 \mathrm{ft}$. L. $\pm 5 \%$.

Test stimuli are presented from the centre of the surface of the hemisphere, i.e., through the lens or from close to it. The subject can be instructed to fixate on either the stimuli themselves (to test central vision) or on any point of the interior surface of the hemisphere which may be indicated by fixing a small black mark at the required position. For standard testing, small $2 \mathrm{v}$. torch bulbs are imbedded into the plaster at $5^{\circ}, 15^{\circ}$, and $35^{\circ}$ along the four diagonals running up and to the left, down and to the left, down and to the right, and up and to the right from the centre of the field lens, and serve as fixation lights. These bulbs are only faintly illuminated when required, and only their filaments can then be seen to glow through $2 \mathrm{~mm}$. apertures in the white paint. Similarly, neon "indicator" lamps are positioned, one each, at $2.5^{\circ}$ from the centre of the fiel lens along each of the four diagonals, so that their top ends lie flush with the interior surface of the hemispheres Pieces of diffusing paper are attached to the top ends of the neon bulbs and have small black crosses painte at their centres.

A specially designed head rest is mounted on supporting platform in such a way that the whole of can rotate about a vertical axis, and part of it (including the chin and brow rests) can rotate about a horizontaf axis. The point of intersection of these axes is also the exact centre of the hemisphere, i.e., at $1 \mathrm{~m}$. from ever point of the interior surface. Either one of the subject? eyes can without difficulty be accurately positioned at this point, since the height of his chair and the deviation of the chin and brow rests from the horizontal and vertical axes are all adjustable. The head rest can be turned and tilted (without the eye shifting from ito required position in relation to the field lens) so that the forehead is square to the optical axis for all fixatiof points. This eliminates that component of ocular fatigue which arises when fixation is maintained by ocula? deviations away from the central position of the eyesin the head.

To ensure that fixation is maintained on the requiped

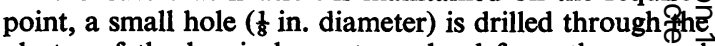
plaster of the hemisphere at eye level from the gromb and at $20^{\circ}$ from the centre of the interior surfecos Through this the subject's fixation can be observed. 0 standard procedure is adopted for the different tost with regard to the few instances when a shift from fixation point is observed, but in practice it is found if the subjects are promptly checked and warned not to " cheat", steady fixation is maintained after the firs? test or so.

An optical system, the position of which relative to the hemisphere is roughly indicated (not to scale) in Fig. permits various light stimum to be presented through the field lens. At the same time $\mathrm{R}$ fills the field lens, which $\overrightarrow{\mathrm{s}}$ seen in Maxwellian view (CB Leibowitz, 1954), with ligh The details of the optical syso tem are illustrated in Fig. $\hat{\Sigma}$

Two channels of light are taken from one source, vertical $2 \mathrm{ft}$. $40 \mathrm{w}$. " naturg Osram" fluorescent tube, and are recombined in a mixing cube. The light of the back ground channel merely passes through wedge filters which permit an exact subjective match to be made between: the brightness of the fielf lens and of the interior of the hemisphere. Cuts 


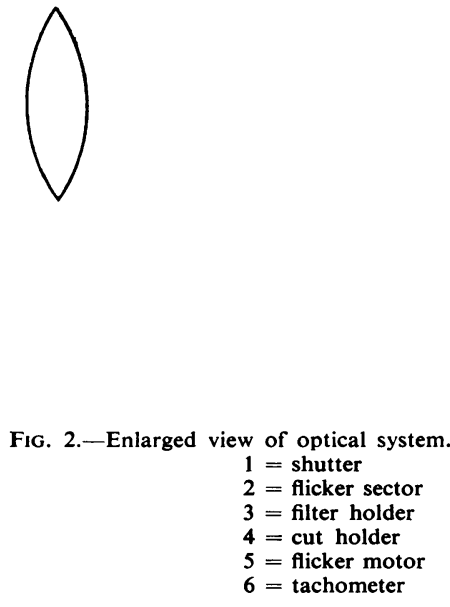

any desired shape or size, and filters of any kind can be inserted into the cut and filter holders positioned along the axis of the stimulus channel. The images of the cuts are seen in the plane of the interior surface of the hemisphere. An electrically operated shutter can be set for stimulus exposures of $1 \mathrm{sec}$. or longer as required.

In order to minimize the 100 cycle component in the output of the $2 \mathrm{ft}$. $40 \mathrm{w}$. fluorescent source, the tube is supplied through a rectifier unit and the output voltage smoothed by means of an electrolytic capacitor. The associated control gear of the lamp unit is retained with the addition of a variable resistor and reversing switch. The residual ripple constitutes $8.5 \%$ of the total light output of this source which has a luminance of 3,162 ft. L. $\pm 2 \%$. The range variation at one session is normally $\pm 0.5 \%$, and control of the source luminance is achieved by use of the variable resistor on the output side of the constant voltage supply to regulate the current passed to the tube. Blackening of the tube is prevented by frequently reversing the direction of the current.

\section{Visual Discrimination Tests and Control Performance}

The particular tests used in this study comprised brightness discrimination (B.D.), flicker fusion (F.F.), acuity for small objects (Ac.), local adaptation (L.A.), tachistoscopic acuity (T.A.), and apparent movement perception (A.M.). A control group of 48 normal individuals, drawn from the staff of the National Hospital, was used in standardizing the tests. Its composition is fully described elsewhere (Ettlinger, 1955). The mean age of this group was 34.7 years, with a range of 17 to 61 years. Each control subject was tested with both eyes separately and on all the tests, each patient with one eye only. Three points along the diagonal meridian of each quadrant $\left(2.5^{\circ}, 15^{\circ}\right.$, and $35^{\circ}$ for B.D., F.F., and L.A.; $5^{\circ}, 15^{\circ}$, and $35^{\circ}$ for Ac., T.A., and A.M.) were selected for standard testing, with the addition of

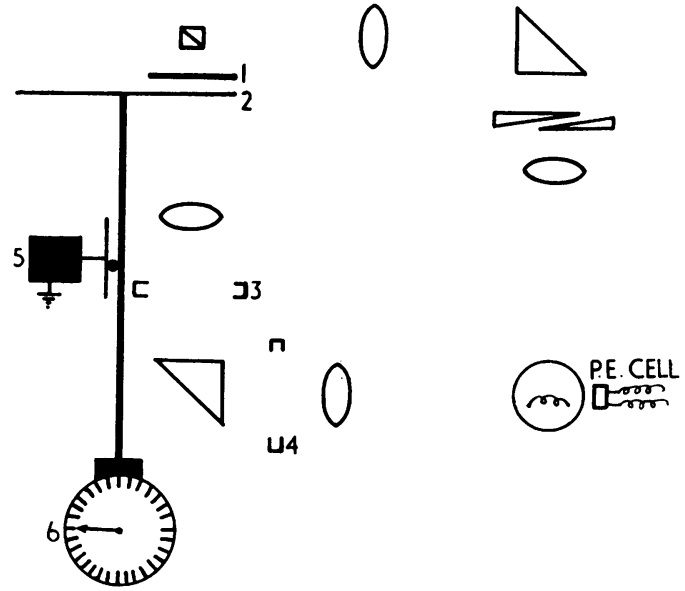

central vision for B.D., F.F., and A.M. The order of testing eyes, quadrants, and points within quadrants was systematically varied for both control subjects and patients to balance practice effects. The sequence of the administration of the different tests was randomly varied. The interval of time between test sessions varied for all subjects from 24 hours to a few weeks. A standard rest period of two minutes is allowed in between the testing of successive quadrants.

In presenting the results for the control group, the findings for the right and left eyes are combined, as are those for the four quadrants tested. This procedure has been adopted because no significant differences were found between results analysed separately for eyes and quadrants, i.e., between upper and lower, right and left, or nasal and temporal quadrants. The thresholds obtained for 48 control subjects using two eyes on each test are also combined because no systematic relationship between performance with the first and second eye could be detected for a random sample of eight of the control group on any test.

The background luminance of the hemisphere and field lens is held constant at $34.7 \mathrm{ft}$. L., but the dimensions of the various test objects presented in the different discrimination tasks are summarized for each test separately below.

The procedure and control results may now be reported for each test.

Brightness Discrimination Tests.-The just-notnoticeable difference in brightness between the test object and the background is determined by the method of serial groups. The luminance of the test object can be decreased from the standard incremental value (measured against an unfilled 


\begin{tabular}{|c|c|c|c|c|}
\hline Test & $\begin{array}{l}\text { Nature of } \\
\text { Test Object }\end{array}$ & $\begin{array}{l}\text { Angular } \\
\text { Size of } \\
\text { Test } \\
\text { Object }\end{array}$ & $\begin{array}{c}\text { Incremental } \\
\text { Luminance } \\
\text { of Test } \\
\text { Object }\end{array}$ & $\begin{array}{l}\text { Duration } \\
\text { of } \\
\text { Exposure }\end{array}$ \\
\hline B.D. & Central circular & 1.5 & Variable & $1.5 \mathrm{sec}$. \\
\hline F.F. & $\begin{array}{l}\text { disc } \\
\text { disc }\end{array}$ & $1.5^{\circ}$ & $\begin{array}{l}199 \cdot 5 \mathrm{ft} \\
\text { (light ph }\end{array}$ & \\
\hline Ac. & $\begin{array}{l}\text { Central modified } \\
\text { Landolt rings }\end{array}$ & Variable & $199.5 \mathrm{ft}$ & $1.5 \mathrm{sec}$ \\
\hline L.A. & $\begin{array}{l}\text { Central circular } \\
\text { disc }\end{array}$ & $1.5^{\circ}$ & ft. $L$. & - \\
\hline T.A. & $\begin{array}{l}2 \text { pairs of neon } \\
\text { lamps, round } \\
\text { field lens }\end{array}$ & $\begin{array}{l}\text { Each lamp } \\
53 \mathrm{~min} .\end{array}$ & $58.9 \mathrm{ft} . \mathrm{L}$. & Variable \\
\hline A.M. & $4 \begin{array}{l}\text { neon lamps } \\
\text { round field lens }\end{array}$ & $\begin{array}{l}\text { Each lamp } \\
53 \mathrm{~min} .\end{array}$ & 58.9 ft. L. & $5 \mathrm{sec}$. \\
\hline
\end{tabular}

field lens) of $199.5 \mathrm{ft}$. L. by the insertion into the stimulus channel of one of a series of neutral density filters. These are graded in steps of $0.25 \mathrm{log}$. units of density.

At each level of luminance the subject is given 10 " presentations", i.e., the shutter is operated 10 times, but in only five of these, at random, is the disc of light actually exposed. The luminance level of the last group of the series (from easy to difficult) in which eight out of 10 responses are correct is recorded as the threshold value. A response "yes" to no exposure is counted incorrect just as is " no" to a faint presentation. No account is taken of errors in groups containing eight correct responses or of correct answers in unsuccessful groups. A period of one to two seconds is allowed between successive presentations and some provisions are made for practice at discrimination on the first quadrant of each test session.

The results at brightness discrimination in central vision and at angular separations of $2.5^{\circ}, 15^{\circ}$, and $35^{\circ}$ from the visual axis for the middle $80 \%$ of the control group are presented in Table I. Ten per cent of all the values obtained have been excluded from each extreme end of this and every other distribution of control data. $\mathrm{N}$ refers to the total number of control values from which the " normal " range of any category of response is derived. As explained above the results for right and left eyes and different quadrants have been combined. In addition, the normal ranges of performance were determined for the following categories of response
(" normal" in this context represents the resules for the middle $80 \%$ of a control group):-

(1) Sum of thresholds at three points in offe quadrant $(\mathrm{N}=383)$; (2) difference between sums off thresholds at three points in the right and leff quadrants (combining upper and lower quadrants when $N=191$ ); (3) difference between threshold at right and left points, comparing $2.5^{\circ}, 15^{\circ}$, arif $35^{\circ}$ each separately $(\mathrm{N}=192,192,191)$.

Flicker Fusion Tests.-Two ascending and two? descending thresholds are obtained, using the methog of minimal changes, for the phenomenal fusion of flickering disc of light. Each presentation of flick has a duration of $1.5 \mathrm{sec}$. with intervals of one two seconds in between successive presentations.

A metal disc having four sectors is driven by $\vec{\theta}$ constant speed motor through a "ball and disc." type of gear box and is mounted as illustrated Fig. 2 so that it interrupts the stimulus light bea close to its narrowest cross-section. The blades this disc give a $1: 1$ light-dark ratio, where the darit phase is the background luminance of the field lens. A Smith's hand tachometer (Model A.T.H.7) is locked to the sector shaft and thus gives a dipect reading of its rate of rotation.

The normal ranges of the mean c.f.f.s in cengrat vision and in the peripheral field are presente Table I. In addition, the normal ranges of the deviations of the individual flicker thresholds fom their mean at any point were ascertained. measure reflects the normal variability of per mance at flicker fusion at one position in the visuan field. The normal ranges for further categories of response were also determined, as for brightne: discrimination, except that no sums of threshols at three points in one quadrant were taken. This additional category of response has been omitted because change of fusion frequency in relation to the eccentricity of the test object was not uniform in the same direction for all subjects as is reported elsewhere (Ettlinger, 1956).

Acuity for Small Objects Test.-In order tö determine the acuity for small objects progressive

TABLE I

NORMAL (80\%) RANGES OF PERFORMANCE BY CONTROL GROUP ON TESTS OF BRIGHTNESS DISCRIMINATIOİ FLICKER FUSION, ACUITY FOR SMALL OBJECTS, LOCAL ADAPTATION AND TACHISTOSCOPIC ACUITY

\begin{tabular}{|c|c|c|c|c|c|c|}
\hline & $\mathrm{N}^{*}$ & $\begin{array}{c}\text { B.D. } \\
(\Delta \mathrm{I} / \mathrm{I}, \\
\text { fractional differences })\end{array}$ & $\begin{array}{l}\text { F.F. } \\
\text { (Mean C.f.f.s } \\
\text { in c.p.s.) }\end{array}$ & $\left|\begin{array}{c}\text { Ac. } \\
\text { (Angular Sizes in } \\
\text { Min. and Sec. of Arc) }\end{array}\right|$ & $\begin{array}{l}\text { L.A. } \\
\text { (Middle Times } \\
\text { in Sec.) }\end{array}$ & $\begin{array}{c}\text { T.A. } \\
\text { (Duration of } \\
\text { Flashes in msec.) }\end{array}$ \\
\hline $\begin{array}{r}\text { Central vision } \\
2.5^{\circ} \\
5^{\circ} \\
15^{\circ} \\
35^{\circ}\end{array}$ & $\begin{array}{r}96 \\
384 \\
384 \\
384 \\
383\end{array}$ & $\begin{array}{l}0.0057-0.018 \\
0.0102-0.032 \\
0.032-0.057 \\
0.057-0.181\end{array}$ & $\begin{array}{l}72 \cdot 5-42 \cdot 5 \\
60 \cdot 5-40 \cdot 0 \\
63 \cdot 5-35 \cdot 5 \\
61 \cdot 5-32 \cdot 5\end{array}$ & $\begin{array}{c}1^{\prime} 4^{\prime \prime}-2^{\prime}, 9^{\prime \prime} \\
8^{\prime} 35^{\prime \prime}-17^{\prime} 10^{\prime \prime} \\
34^{\prime} 20^{\prime \prime}-137^{\prime} 20^{\prime \prime}\end{array}$ & $\begin{array}{l}120+-11 \\
30-5 \\
20-4\end{array}$ & $\begin{array}{c}1 \cdot 5-5 \cdot 4 \\
5 \cdot 4-14 \cdot 5 \\
14 \cdot 5-80 \cdot 0\end{array}$ \\
\hline
\end{tabular}

* $\mathrm{N}$ refers to the number of thresholds on which any range isbased. 
smaller "modified" Landolt rings are presented by the method of serial groups from the centre of the field lens. The gap in the ring faces twice in each direction (in random order) in each group, and testing is continued until the direction of the gap cannot be correctly discriminated in six out of the eight trials allowed for any one size of gap.

The modified Landolt rings are prepared from thin copper foil and are then attached to glass slides. Since the image of any cut has dimensions about three times greater than those of the cut itself owing to the characteristics of the optical system, modified Landolt rings were developed in which the angular size of the rings is maintained constant (at $2.3^{\circ}$ outer, $1.5^{\circ}$ inner diameter) for variations in the magnitude of the gap ranging from $1 \mathrm{~min} .4 \mathrm{sec}$. to $68 \mathrm{~min}$. $40 \mathrm{sec}$. Unfortunately certain disadvantages are inherent in this design.

Small differently coloured marks can be attached to the surface of the hemisphere close to the lens in the four directions, e.g., red to the left, blue to the right, etc., to assist those patients who have right/ left disorientation.

The normal ranges of performance are given in Table I. The normal ranges for additional categories of response were also determined, as for brightness discrimination.

Local Adaptation Test.-In the test of local adaptation three values for the time of subjective disappearance of a disc of light after its exposure are recorded for each position of the visual field tested. Taking one quadrant at a time, the positions along it are tested once each in rotation and then for the second and third times again in rotation.

The subject is given standard instructions part of which read: "If the bright central disc appears to you to fade from view into the background I want you to press this key here. If the disc does not appear to fade from view into the background within a certain time, I shall switch it off. You should avoid blinking more frequently than is necessary, and you should not press the key if the disc has disappeared from view only during a blink. On the other hand, you should press the key if the bright central disc has appeared to fade from view into the background even for a moment only and then has reappeared." An electrical clock is started synchronously with the exposure of the disc and stopped by the subject when he presses the key.

The maximum exposure time is $120 \mathrm{sec}$, and a response category of $120+$ is recorded if the subject has failed to press the key within this interval. In order to ensure that the prolonged local adaptation times manifested by some patients are not the result of inadequate comprehension of instructions but are genuinely visual phenomena, the disc can be silently obscured. Such checks are only made after the disc has been exposed for $120 \mathrm{sec}$., and the threshold value is discounted if the subject has failed to press the key within $5 \mathrm{sec}$. of the obscuration.

In computing the normal ranges of performance (Table I) account has been taken of only the middle one of the three values recorded at any position in the field of vision. The normal ranges of variability at local adaptation were ascertained by including the deviations of the two remaining readings from the middle time at each position in one frequency distribution. In addition, the normal ranges for other categories of response were also determined, as for brightness discrimination.

Tachistoscopic Acuity Test.-Tachistoscopic acuity is evaluated by flashing one of two pairs of neon lamps on for progressively shorter durations until the stimulus pair cannot be identified correctly in eight out of the 10 trials allowed for any one duration of flash.

The $240 \mathrm{v}$. neon indicator lamps positioned at $2.5^{\circ}$ along the four diagonal meridians from the centre of the field lens are employed. They are wired for this test in pairs, the bulbs at the diagonally opposite corners of the square being connected together. Each pair is presented five times (in random order) in each group of 10 trials. Their light has an orange red appearance.

The neon tube circuit is completed by means of a pair of high speed relay contacts, and the current pulse for the operating coil of this relay is drawn from a capacitor charged to a suitable potential. Variation of the flash duration is achieved by selecting the appropriate one of five capacitors giving times ranging from 1.5 to $80 \mathrm{msec}$. In the course of the investigation all flash durations have varied by approximately $\pm 5 \%$, and a further disadvantage relates to the relatively large angular size of the test pairs.

The normal ranges of performance are shown in Table I. The normal ranges for additional categories of response were also determined, as for brightness discrimination.

Apparent Movement Perception Test.-The four neon lamps at $2.5^{\circ}$ from the centre of the field lens are illuminated in anti-clockwise rotation in order to test apparent movement perception. The standard parameters of stimulation, i.e., exposures lasting $160 \mathrm{msec}$. and intervals between exposures of $40 \mathrm{msec}$., are such as have been found to give optimal perception of apparent movement with a small pilot group. Only one presentation, lasting 5 sec., is made under the standard conditions at each position in the visual field, and the subject is then 
immediately questioned about his experience. Answers are sought according to five categories of experience, but leading questions are avoided and the subject is not pressed to answer if he is uncertain.

The four neon lamps are supplied through contacts on an electrically driven cam operated switch, and variation of the motor speed will adjust the period of the complete stimulus cycle (from 0.6 to $2.0 \mathrm{sec}$.). On the other hand, movement of the wedge-shaped operating cam in relation to the switch contacts allows the on-off ratio of the lamps to be altered (from 0.46 to $1 \cdot 16$, i.e., so that successive flashes may overlap).

The relative frequencies of two out of the five categories of response for the control group are presented in Table II, where $\mathbf{N}$ refers to the number of positive responses on which any percentage is based.

TABLE II

CONTROL RESULTS ON TEST OF APPARENT MOVEMENT PERCEPTION (\% INCIDENCE OF ALTERNATIVE RESPONSES)

\begin{tabular}{|c|c|c|c|c|c|}
\hline & $\mathbf{N}$ & $\begin{array}{c}\text { Move- } \\
\text { ment }\end{array}$ & \multicolumn{3}{|c|}{ No Movement } \\
\hline $\begin{array}{c}\text { Central } \\
5^{\circ} \\
15^{\circ} \\
35^{\circ}\end{array}$ & $\begin{array}{r}94 \\
384 \\
384 \\
383\end{array}$ & $\begin{array}{l}91.5 \\
95.3 \\
99.7 \\
94.0\end{array}$ & \multicolumn{3}{|c|}{$\begin{array}{l}8 \cdot 5 \\
4 \cdot 7 \\
0 \cdot 3 \\
6 \cdot 0\end{array}$} \\
\hline & $\mathbf{N}$ & $\begin{array}{l}\text { Square } \\
\text { Shape }\end{array}$ & Circle & Others & $\begin{array}{c}\text { No } \\
\text { Shape }\end{array}$ \\
\hline $\begin{array}{c}\text { Central } \\
5^{\circ} \\
15^{\circ} \\
35^{\circ}\end{array}$ & $\begin{array}{r}86 \\
367 \\
376 \\
355\end{array}$ & $\begin{array}{r}79 \cdot 1 \\
62 \cdot 1 \\
22 \cdot 6 \\
9 \cdot 9\end{array}$ & $\begin{array}{l}18 \cdot 6 \\
30 \cdot 8 \\
66 \cdot 2 \\
56 \cdot 1\end{array}$ & $\begin{array}{l}0 \cdot 0 \\
4 \cdot 1 \\
9 \cdot 1 \\
8 \cdot 5\end{array}$ & $\begin{array}{r}2 \cdot 3 \\
3 \cdot 0 \\
2 \cdot 1 \\
25 \cdot 5\end{array}$ \\
\hline
\end{tabular}

The response category of " movement" includes any impression of movement, whatsoever its nature. The most common alternative report was to the effect that the lights merely flashed on and off successively. When a response of "no movement" was given, the temporal parameters of stimulation were varied over the ranges described above. In about one half of these cases the perception of movement could then be evoked, but no systematic trend became evident implicating either shorter or longer durations of illumination or of intervals between illuminations as more effective in promoting the perception of movement than the standard conditions. Mere repetition of presentations to one retinal position may, therefore, exert a facilitating effect, independently, within certain limits, of the temporal parameters of stimulation. At all positions some responses of "no shape" probably reflect uncertainty rather than a positive absence of perceived shape.

In about $10 \%$ of all responses a phenomenal change in the display occurred during the 5 s. presentation. In such cases only the predominatiōg appearance was included in the results analysed. A number of subjects also spontaneously reportef( diminution in the apparent size of the display $7 \mathrm{at}$ $35^{\circ}$ by comparison with its appearance at $15^{\circ}$ and $5^{\circ}$. Information concerning the other categor of response is given by Ettlinger (1955).

\section{Test-Retest Correlations}

The rank test-retest correlations were calculated on all the tests excepting apparent movement pe्fception for a group of eight control subjects select高 at random. Applying one-tailed tests of significanoe and adopting the conventional $5 \%$ level of copfidence, these test-retest correlations proved sfgnificant in every instance with the exception of acuity for small objects.

\section{Selection of Cases}

A group of 30 patients has been studied. Of these only one (Case 23) was selected for the presence of visual perceptual disorder and was referred Dr. C. A. Pallis for examination (Pallis, 1955). T侟 remainder comprised 22 cases of cerebral disgase and five cases of brain injury. Two cases presented visual deficits associated with optic atrophy. one exception (Case 30$)^{*}$ no case with severe iftet lectual deterioration was included, although thege were minor degrees of impairment in several. $T \& \mathbb{e}^{\mathbb{S}}$ were not, however, thought to be sufficient to dise cooperation on the tests.

The cases were divided into three groups on the basis of the presence of visual field defects and/or evidence of higher perceptual disorder. Group $A$ comprises 12 cases lacking both field defects and evidence of perceptual disorder; group B comprises 10 cases with various types of field defect bout without evidence of perceptual loss other than theit directly attributable to the field defects; group comprises eight cases in which both field defec\$s and various types of higher perceptual disorder weře in evidence. The salient data in the individual cases in each group are summarized in Tables III, IV and $\mathrm{V}$.

No pupillary abnormalities were present in the eye tested of any patient apart from Case 17, an disturbance of eye movements during fixation wass observed only in Case 24 . Reasonable allowance for various other clinical features such as dysphasia (Cases 1, 2, and 25) and right/left disorientation was made by slight alterations of procedure, but tes were abandoned in all instances in preference to the

* Case 30 has been included because he demonstrates that sensory thresholds can be determined for patients of extremely defectidy intelligence. 
introduction of any significant departure from the standard procedures. Results of clinical tests of central visual acuity were available in every case and are given in detail elsewhere (Ettlinger, 1955). No exceptional values were reported.

\section{Procedure and Treatment of Results}

In general the patient's more "effective" eye (by reference to clinical tests of acuity or perimetry) was selected for testing, but where vision seemed to be essentially the same in the two eyes the choice was made by a random procedure. An exception to this rule was made in one case of optic atrophy (Case 19) when the eye with least effective vision was chosen for tests of both perception and sensory efficiency.

Although thresholds were obtained for some patients at positions in the visual field additional to the standard points used with the control group, e.g., for the vertical and horizontal meridians, these data have been neglected in computing two overall measures of visual sensory performance for each patient, the " efficiency index" and the "variability index". Details of the method of calculating these indices are given by Ettlinger (1955). In outline, however, the patient's performance is compared with the appropriate normal range, taking the threshold obtained at each of the standard positions in the visual field separately, as also certain additional categories of response.*

If performance at any point or according to any additional category of response falls within the normal range it is allotted a "transformed" score of zero; if it falls outside the normal range in the direction of less efficient performance or of greater variability between successive discriminations, it is allotted a transformed score of -1 ; if it falls outside the normal range in the direction of more efficient performance or of less variability between successive discriminations it is allotted a transformed score of +1 . The algebraic sums of these transformed scores, taking scores relating to efficiency and variability separately, are found either for one test at a time or for all tests in combination. $\dagger$

In order to eliminate the positive or negative

\footnotetext{
* These have been mentioned in the description of the sensory tests. There are four scores in each test (excluding flicker fusion and apparent movement) for the sums of three thresholds in one quadrant. Comparisons between performance in the left and right half-fields are always allotted two scores, whether quadrants or individual sites are contrasted. In the test of apparent movement perception only " movement" and "shape" responses are compared with control data. One measure of variability is taken for each threshold, where applicable, for computing variability indices.

† One " transformed" score is also allotted for performance on a test of real movement perception in central vision, and this is included in the algebraic sums of "transformed" scores for all the tests in combination.
}

signs of the algebraic sums of transformed scores, and to allow for the varying numbers of transformed scores on which these sums may be based, a mathematical conversion to indices is effected. Thus a positive algebraic sum of transformed scores is added to the total of transformed scores on which it is based and the resulting value is expressed as a ratio of this total, times 100 ; if the sum of transformed scores is negative, it is subtracted from the total number of transformed scores on which it is based, and the difference is expressed as a ratio of this total, times 100. An index of 100 then represents the level of performance relating to the middle $80 \%$ of the control data, and values greater or smaller than 100 are related to more or less efficient or consistent levels of performance respectively. However, owing to a scoring bias which affects all the patients' results equally, efficiency indices greater than 100 in value are slightly less probable than values below 100.*

In computing efficiency indices, a transformed score of -1 is allotted both for performance relating to a totally blind area of the visual field and for a threshold determination falling just outside the normal range of performance. Account is, however, taken of the difference between these two kinds of result in charting each patient's performance at different sites in the visual field with a graphical technique described elsewhere (Ettlinger, 1955).

\section{Results}

The efficiency indices on the individual tests and on all the tests in combination for the 30 patients are given in Tables III, IV, and V. It will be seen from Table III that the mean overall efficiency index for the 12 cases with perimetrically normal fields is found to be 82 . This signifies that there is some overall impairment of sensory efficiency relative to the standard of the control subjects despite the lack of field defects as conventionally determined. It is improbable that the sensory impairment of patients in Group A is related to the slightly greater mean age $(38.2 \mathrm{yr}$.) in this group than in the control group. The effect of the scoring bias may also be discounted since the mean efficiency index for 11 of the 12 patients tested at brightness discrimination is still only 89 , although the bias is negligible in this test. These scores on brightness discrimination (which may be shown to be significantly lower than control values at the $1 \%$ level

* Owing to the significant excess of positive transformed scores at L.A. (see below), algebraic sums of transformed scores derived by a different method are incorporated into the overall efficiency indices. Thus both positive and negative transformed scores are treated as negative, but the negative total is reduced by a constant factor to allow for the $20 \%$ expectation of both positive and negative transformed scores. 
TABLE III

EFFICIENCY INDICES FOR INDIVIDUAL TESTS AND FOR TESTS IN COMBINATION IN CASES WITHOUT FIELD DEFEETS OR PERCEPTUAL LOSS (GROUP A)

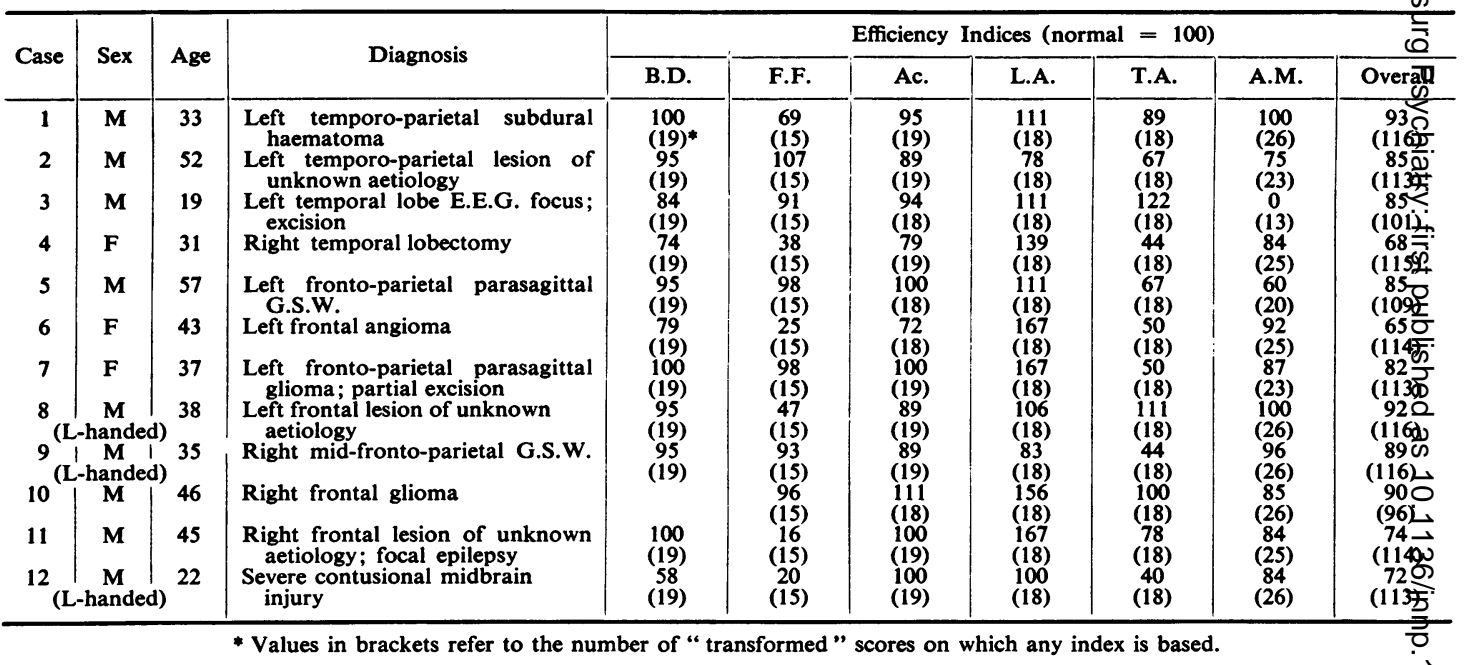

TABLE IV EFFICIENCY INDICES FOR INDIVIDUAL TESTS AND FOR ALL TESTS IN COMBINATION IN CASES WITH FIELD DEFEGTS
BUT WITHOUT PERCEPTUAL LOSS (GROUP B)

\begin{tabular}{|c|c|c|c|c|c|c|c|c|c|c|c|}
\hline \multirow{2}{*}{ Case } & \multirow{2}{*}{ Sex } & \multirow{2}{*}{ Age } & \multirow{2}{*}{ Diagnosis } & \multirow{2}{*}{ Field Defects } & \multicolumn{6}{|c|}{ Efficiency Indices (normal $=100$ ) } & $\frac{\Omega_{1}}{2}=$ \\
\hline & & & & & B.D. & F.F. & Ac. & L.A. & T.A. & A.M. & \\
\hline 13 & $\mathbf{M}$ & 27 & $\begin{array}{l}\text { Left occipito-parietal para- } \\
\text { sagittal G.S.W. }\end{array}$ & Partial R. homonymous & 26 & $\begin{array}{c}43 \\
(15)\end{array}$ & 26 & 89 & 6 & 83 & \\
\hline 14 & $\mathbf{F}$ & 13 & $\begin{array}{l}\text { Right occipital lesion of } \\
\text { unknown aetiology }\end{array}$ & $\begin{array}{l}\text { Concentric constriction more } \\
\text { marked to left }\end{array}$ & $\begin{array}{l}63 \\
(19)\end{array}$ & $\begin{array}{l}40 \\
(51)\end{array}$ & $\begin{array}{l}42 \\
(19)\end{array}$ & - & $\begin{array}{l}47 \\
(18)\end{array}$ & $\begin{array}{c}65 \\
(23)\end{array}$ & $\frac{8}{6}$ \\
\hline 15 & $\mathbf{F}$ & 43 & $\begin{array}{l}\text { Right parieto-occipital neo- } \\
\text { plasm }\end{array}$ & L. homonymous hemianopia & $\begin{array}{l}42 \\
(19)\end{array}$ & 14 & $\begin{array}{l}37 \\
(19)\end{array}$ & $\begin{array}{c}50 \\
((18)\end{array}$ & $\begin{array}{l}39 \\
(18)\end{array}$ & $\begin{array}{c}65 \\
(20)\end{array}$ & 量这 \\
\hline 16 & $\mathbf{F}$ & 45 & $\begin{array}{l}\text { Right mid-parietal menin- } \\
\text { gioma; excision }\end{array}$ & $\begin{array}{l}\text { L. homonymous lower quad- } \\
\text { rantic defect }\end{array}$ & $\begin{array}{l}47 \\
(19)\end{array}$ & 17 & $\begin{array}{l}67 \\
(18)\end{array}$ & $\begin{array}{l}94 \\
(18)\end{array}$ & - & $\begin{array}{l}88 \\
(25)\end{array}$ & .670 \\
\hline 17 & $\mathbf{M}$ & 30 & $\begin{array}{l}\text { Right mid-fronto-parietal } \\
\text { G.S.W. }\end{array}$ & $\begin{array}{l}\text { L. homonymous lower quad- } \\
\text { rantic defect }\end{array}$ & $\begin{array}{l}61 \\
(19)\end{array}$ & $\begin{array}{l}67 \\
(15)\end{array}$ & $\begin{array}{l}58 \\
(19)\end{array}$ & $\begin{array}{l}75 \\
(18)\end{array}$ & $\begin{array}{l}17 \\
(18)\end{array}$ & $\begin{array}{l}92 \\
(24)\end{array}$ & \\
\hline 18 & $\mathbf{M}$ & 26 & $\begin{array}{l}\text { Cerebral lesion of unknown } \\
\text { aetiology: epilepsy }\end{array}$ & Inconstant defects & $\begin{array}{l}58 \\
(19)\end{array}$ & $\begin{array}{l}36 \\
(15)\end{array}$ & $\begin{array}{l}37 \\
\text { (19) }\end{array}$ & $\begin{array}{l}83 \\
(18)\end{array}$ & $\begin{array}{l}50 \\
(18)\end{array}$ & $\begin{array}{l}83 \\
(23)\end{array}$ & 6 \\
\hline 19 & $\mathbf{M}$ & 27 & $\begin{array}{l}\text { Suprasellar meningioma; right } \\
\text { subtotal frontal lobectomy }\end{array}$ & Bitemporal constriction & $\begin{array}{l}21 \\
(19)\end{array}$ & (15) & $\begin{array}{l}47 \\
(19)\end{array}$ & $\begin{array}{l}167 \\
(18)\end{array}$ & $\begin{array}{l}17 \\
(18)\end{array}$ & $\begin{array}{c}50 \\
(18)\end{array}$ & $\left(10 \frac{3}{3}\right.$ \\
\hline 20 & $\mathbf{M}$ & 61 & $\begin{array}{l}\text { Optic atrophy related to } \\
\text { pituitary adenoma }\end{array}$ & $\begin{array}{l}\text { Right eye blind, concentric } \\
\text { constriction more marked }\end{array}$ & (19) & $\begin{array}{c}7 \\
(14)\end{array}$ & $\begin{array}{l}26 \\
(19)\end{array}$ & $\begin{array}{l}67 \\
(18)\end{array}$ & & $\begin{array}{l}53 \\
(19)\end{array}$ & (9क्ष \\
\hline 21 & $\mathbf{M}$ & 18 & Right temporal lobectomy & $\begin{array}{l}\text { Left homonymous upper quad- } \\
\text { rantic defect }\end{array}$ & $\begin{array}{c}58 \\
(19)\end{array}$ & $\begin{array}{c}95 \\
(14)\end{array}$ & $\begin{array}{c}74 \\
(19)\end{array}$ & $\begin{array}{c}83 \\
(18)\end{array}$ & $\begin{array}{c}67 \\
(18)\end{array}$ & $\begin{array}{l}67 \\
(21)\end{array}$ & $\frac{0}{9}$ \\
\hline 22 & $\mathbf{M}$ & 30 & Right temporal lobectomy & $\begin{array}{l}\text { Partial left homonymous } \\
\text { hemianopia }\end{array}$ & $\begin{array}{l}42 \\
(19)\end{array}$ & $\begin{array}{l}63 \\
(15)\end{array}$ & $\begin{array}{l}63 \\
(19)\end{array}$ & $\begin{array}{l}78 \\
(18)\end{array}$ & $\begin{array}{l}11 \\
(18)\end{array}$ & $\begin{array}{l}30 \\
(21)\end{array}$ & $\begin{array}{r}560 \\
(1083\end{array}$ \\
\hline
\end{tabular}

* Values in brackets refer to the number of " transformed" scores on which any index is based.

of confidence) also exclude the effect of the abnormal results at flicker fusion and local adaptation in cases with frontal pathology (see below).

The relative frequencies of the negative transformed scores relating to thresholds taken in the half-field of vision on the same and on the opposite side to a unilateral lesion were also compared in this group of cases. Performance on all the tests excepting only local adaptation was found to be very slightly more depressed in the half-field contralateral to the lesion than in the ipsilateral half-field. Statistical analysis, however, failed to demonstrate that this difference in performa between the two half-fields on all the tests is signini-

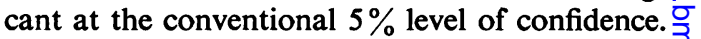

The results in Group B are presented in Table E. As expected, visual discrimination is more severely impaired in this group than in Group A, the mean overall efficiency index being only 54 . On the otfer hand, the presence of perceptual disorder additional to field defects is not associated with a significant further loss of visual efficiency. Thus the mesn overall efficiency index of the eight patients In Group C (Table V) is 51 , only three points below 
TABLE V

EFFICIENCY INDICES FOR INDIVIDUAL TESTS AND FOR ALL TESTS IN COMBINATION IN CASES WITH FIELD DEFECTS AND PERCEPTUAL LOSS (GROUP C)

\begin{tabular}{|c|c|c|c|c|c|c|c|c|c|c|c|c|}
\hline \multirow{2}{*}{ Case } & \multirow{2}{*}{ Sex } & \multirow{2}{*}{ Age } & \multirow{2}{*}{ Diagnosis } & \multirow{2}{*}{ Field Defects } & \multirow{2}{*}{ Perceptual Disorders } & \multicolumn{7}{|c|}{ Efficiency Indices (normal $=100$ ) } \\
\hline & & & & & & B.D. & F.F. & Ac. & L.A. & T.A. & A.M. & Overall \\
\hline 23 & $\mathbf{M}$ & 52 & $\begin{array}{l}\text { Bilateral occi- } \\
\text { pital infarcts }\end{array}$ & $\begin{array}{l}\text { Bilateral para- } \\
\text { central scotoma } \\
\text { in upper quad- } \\
\text { rants; L. upper } \\
\text { q u a d r a n t i c } \\
\text { defect }\end{array}$ & $\begin{array}{l}\text { Prosopagnosia, achroma- } \\
\text { topsia, topographical } \\
\text { loss }\end{array}$ & $\begin{array}{l}42 \\
(19)^{*}\end{array}$ & $\begin{array}{c}38 \\
(14)\end{array}$ & $\begin{array}{c}26 \\
(19)\end{array}$ & $\begin{array}{c}94 \\
(18)\end{array}$ & $\begin{array}{c}22 \\
(18)\end{array}$ & $\begin{array}{c}41 \\
(17)\end{array}$ & $\begin{array}{c}36 \\
(106)\end{array}$ \\
\hline 24 & $\mathbf{M}$ & 63 & $\begin{array}{l}\text { Occlusion of } \\
\text { basilar artery }\end{array}$ & $\begin{array}{l}\text { R. homonymous } \\
\text { hemianopia }\end{array}$ & & $\begin{array}{c}32 \\
(19)\end{array}$ & $\begin{array}{c}53 \\
(15)\end{array}$ & $\begin{array}{l}11 \\
(18)\end{array}$ & $\begin{array}{l}100 \\
(18)\end{array}$ & $\begin{array}{l}28 \\
(18)\end{array}$ & $\begin{array}{l}27 \\
(15)\end{array}$ & $\begin{array}{c}33 \\
(103)\end{array}$ \\
\hline 25 & $\mathbf{M}$ & 53 & Cortical atrophy & $\begin{array}{l}\text { L. lower quad- } \\
\text { rantic defect in } \\
\text { L. eye }\end{array}$ & $\begin{array}{l}\text { Simultanagnosia, visual } \\
\text { constructive defects }\end{array}$ & $\begin{array}{l}37 \\
(19)\end{array}$ & $\begin{array}{l}67 \\
(15)\end{array}$ & $\begin{array}{l}100 \\
(1)\end{array}$ & $\begin{array}{l}89 \\
(18)\end{array}$ & & $\begin{array}{l}87 \\
(23)\end{array}$ & $\begin{array}{l}74 \\
(76)\end{array}$ \\
\hline 26 & $\mathbf{M}$ & 49 & $\begin{array}{c}\text { Supratentorial } \\
\text { meningioma }\end{array}$ & $\begin{array}{l}\text { Concentric con- } \\
\text { striction more } \\
\text { marked to L. }\end{array}$ & $\underset{\text { defect }}{\text { Visual constructive }}$ & $\begin{array}{l}37 \\
\text { (19) }\end{array}$ & $\begin{array}{c}33 \\
(15)\end{array}$ & $\begin{array}{l}26 \\
(19)\end{array}$ & $\begin{array}{l}11 \\
(18)\end{array}$ & $\begin{array}{l}11 \\
(18)\end{array}$ & $\begin{array}{c}50 \\
(20)\end{array}$ & $\begin{array}{c}32 \\
(110)\end{array}$ \\
\hline 27 & $\mathbf{M}$ & 49 & $\begin{array}{l}\text { R. parietal cystic } \\
\text { glioma }\end{array}$ & $\begin{array}{l}\text { L. homonymous } \\
\text { attention hemi- }\end{array}$ & $\begin{array}{l}\text { Unilateral visual neglect, } \\
\text { visual-spatial agnosia, }\end{array}$ & $\begin{array}{l}74 \\
(19)\end{array}$ & $\begin{array}{c}89 \\
(15)\end{array}$ & $\begin{array}{c}32 \\
(19)\end{array}$ & $\begin{array}{l}100 \\
(18)\end{array}$ & $\begin{array}{c}22 \\
(18)\end{array}$ & $\begin{array}{c}75 \\
(24)\end{array}$ & $\begin{array}{l}65 \\
(113)\end{array}$ \\
\hline 28 & $\mathbf{M}$ & 61 & $\begin{array}{l}\text { R. parietal } \\
\text { angioma }\end{array}$ & $\begin{array}{l}\text { L. homonymous } \\
\text { hemianopia }\end{array}$ & $\begin{array}{l}\text { Unilateral visual neglect, } \\
\text { visual-spatial agnosia }\end{array}$ & $\begin{array}{c}21 \\
(19)\end{array}$ & $\begin{array}{l}67 \\
(15)\end{array}$ & $\begin{array}{c}26 \\
(19)\end{array}$ & $\begin{array}{l}67 \\
(18)\end{array}$ & $\begin{array}{c}44 \\
(18)\end{array}$ & $\begin{array}{l}67 \\
(21)\end{array}$ & $\begin{array}{l}47 \\
(110)\end{array}$ \\
\hline 29 & $\mathbf{F}$ & 51 & $\begin{array}{l}\text { R.occipito- } \\
\text { parietal glioma }\end{array}$ & $\begin{array}{l}\text { Partial L. homo- } \\
\text { nymous hemi- }\end{array}$ & $\begin{array}{l}\text { Visual-spatial agnosia, } \\
\text { topographical loss }\end{array}$ & $\begin{array}{l}47 \\
\text { (19) }\end{array}$ & $\begin{array}{l}47 \\
(15)\end{array}$ & $\begin{array}{l}58 \\
\text { (19) }\end{array}$ & $\begin{array}{l}67 \\
(18)\end{array}$ & $\begin{array}{l}44 \\
(18)\end{array}$ & $\begin{array}{l}71 \\
(21)\end{array}$ & $\begin{array}{l}59 \\
(110)\end{array}$ \\
\hline 30 & $\mathbf{M}$ & 49 & Cortical atrophy & $\begin{array}{l}\text { R. homonymous } \\
\text { hemianopia }\end{array}$ & $\begin{array}{l}\text { Multiple defects of visual } \\
\text { perception, dementia }\end{array}$ & (19) & $\begin{array}{c}77 \\
(15)\end{array}$ & & $\begin{array}{l}83 \\
(18)\end{array}$ & & & $\begin{array}{c}61 \\
(52)\end{array}$ \\
\hline
\end{tabular}

* Values in brackets refer to the number of " transformed" scores on which any index is based.

the mean value for Group B. Individual results for patients in this group, and their significance in relation to the origins of agnosia, are discussed below.

The results given by all patients on all tests are analysed in order to determine the relative sensitivity of the different tests as indicators of visual loss. The mean efficiency indices of all patients and of Groups A, B, and C separately on each test are given in Table VI. It will be seen that tachistoscopic

TABLE VI

SENSITIVITY OF TESTS AS INDICATORS OF VISUAL DEFECT FOR ALL PATIENTS AND FOR GROUPS A, B, AND C SEPARATELY

\begin{tabular}{l|c|c|c|c}
\hline & \multicolumn{2}{|c|}{ Mean Efficiency Indices (normal=100) } \\
\cline { 2 - 5 } & $\begin{array}{c}\text { All } \\
\text { Cases }\end{array}$ & $\begin{array}{c}\text { Group } \\
\text { A }\end{array}$ & $\begin{array}{c}\text { Group } \\
\text { B }\end{array}$ & $\begin{array}{c}\text { Group } \\
\text { C }\end{array}$ \\
\hline (1) Tachistoscopic acuity & 46 & 72 & 32 & 29 \\
(2) Flicker fusion & 56 & 67 & 40 & 59 \\
(3) Brightness discrimination & 59 & 89 & 43 & 38 \\
(5) Acuity for small objects & 65 & 85 & 48 & 30 \\
(5) Apparent movement & 69 & 82 & 68 & 60 \\
(6) Local adaptation & 100 & 125 & 87 & 76 \\
\hline
\end{tabular}

acuity appears the most, and local adaptation the least, sensitive indicator of defect in visual discrimination when all 30 patients are combined. In the cases of Group A, however, the lowest score is found on the test of flicker fusion. This alteration in the order of sensitivity of the tests is probably the result of a predominance of cases with frontal pathology in Group A (see below). The most striking finding in the cases of Group $\mathrm{C}$ is the depression of performance on three tests (T.A., Ac, and B.D.) in combination relative to the scores on the remaining three tests. Such a difference is not seen in either Group A or B, and it is most marked on the tests of acuity for small objects and brightness discrimination. For the scores on these two tests are relatively high in Groups A and B, whereas the mean efficiency index at tachistoscopic acuity is uniformly low for all 30 patients.

Differential analysis by site and laterality of lesion reveals only one significant difference of performance on the discrimination tests between appropriate sub-groupings of patients, when the presence of field defects is allowed for by taking a relative measure between the overall efficiency index and that relating to any specific test. Thus a significant increase in length of fading times on the local adaptation test is found in cases of exclusively frontal-lobe pathology. Nevertheless, prolongation of fading times is not entirely confined to frontal cases and may be demonstrated to be in excess of control results for all 30 patients in combination $\left(x^{2}-122,1\right.$ d.f.). Patients with frontal lesions, moreover, tend towards low thresholds and small deviations of successive judgments on the flicker fusion test in comparison with the results given by patients with lesions elsewhere. This difference is, however, just below significance at the $5 \%$ level of confidence. The converse trend on the test of brightness discrimination, namely for frontal cases to score more highly than patients with temporal lobe lesions (but excluding cases with perimetric defects), also fails to prove statistically significant. 


\section{Discussion}

We may now inquire what light our results throw upon the origin of agnosic disorders. As we have seen, some degree of sensory deficit has been established in 12 cases of cerebral lesion in the absence of visual field defects. Where field defects are present, moreover, an even greater sensory deficit, as established by our methods of examination, was ascertained in 10 cases. On the other hand, no significant increase in sensory deficit could be established in eight cases in which field defects were associated with higher perceptual disorders. It would therefore appear, on first inspection at least, that sensory deficits of the type adduced by Bay as responsible for visual agnosia do not play a significant role in the genesis of this disorder.

At the same time, it must be borne in mind that no true case of visual object agnosia in the classical sense of the term is included in our series. In the one case of " prosopagnosia" (Case 23), moreover, the overall efficiency index was undoubtedly low. This might be interpreted as evidence in support of Bay's view that defects in physiognomic recognition arise on a sensory basis. None the less, three patients in our series (Cases 19, 24, and 26) gave evidence of an even greater reduction in sensory efficiency without the least trace of prosopagnosia.* It is also noteworthy that one patient (Case 18) gave no evidence of visual agnosia at a time at which fluctuating alterations of sensory function were present over the entire visual field. Further, the combination of sensory defects and intellectual loss in certain of our patients (in particular Cases 19 and 20), was not found to give rise to agnosia in the manner suggested by Bay. It would therefore appear that impairment of visual discrimination, while present in many cases with disturbances in visual perception, is not in itself adequate to provoke the symptoms of agnosia.

The results in three cases presenting the syndrome of visual-spatial agnosia (as defined by McFie, Piercy, and Zangwill, 1950) do not suggest that sensory defects are of appreciable significance in its origin. The overall efficiency indices of three patients who presented this syndrome (Cases 27, 28, and 29) are respectively 65,47 , and 59 . Although these values are low, they are certainly well above those given by several patients in Group $B$ who had sustained field defects unaccompanied by spatial

\footnotetext{
* It can of course be held that the precise distribution of sensory loss in the visual fields has greater significance for agnosia than overall reduction in visual efficiency. Thus in the case under discussion, it might be argued that the combination of paracentral scotomata with sensory deficit in perimetrically normal areas of the peripheral field is sufficient to constrain prosopagnosia. This interpretation is not, however, supported by Pallis (1955) in his discussion of this case.
}

loss. Moreover, no consistent relationship betwe any one pattern of sensory deficit and visual-spatial agnosia can be detected. It would therefore appear that there is no direct association between reduction of visual efficiency and disorders of spatial judgment.

It might still be argued that the various disorde्तs of visual perception are attributable to intellectuml deficit of a global character. This claim cannot He fully discussed in the present context, but intellectual testing (fully reported elsewhere) revealed no greatestr intellectual impairment in cases comprising GroupjC than in either Group A or B. It is therefore unlik that higher disorders of perception are the expression of global intellectual loss.

In connexion with Bay's reliance on the metho్d of local adaptation, it should perhaps be poinked out that successive fading times determined at the same position in the visual field commonly vaty considerably, even in healthy subjects. Thefs variations of up to $31 \mathrm{sec}$. between successive fading times are normal at $2 \cdot 5^{\circ}$, and of up to $10 \mathrm{sec}$. at $15^{\circ}$ positions. Moreover, this method has been shown to discriminate the least successfully of opr tests between healthy and brain-damaged inidividuals. Its reliability, as indicated by test-retest correlation, is also lower than that of any test excepting acuity for small objects. It imay therefore be suggested that future studies of significance of sensory defects in agnosia sh్g not be limited to the use of this test alone.

The level of the neurophysiological changes in visual system underlying the sensory deficits established in this study provides an important prōis for future investigation. Whether, for example, local adaptation is peripheral or cerebral in origin is not at present known with certainty. The extênt to which the defects described in this paper क्षe specific to the visual modality has also to be ascorrtained. All that can be said with confidence is that defects in visual discrimination are commonty encountered in cases of cerebral lesion and may elicited in perimetrically normal areas of the vis gal field. We are thus able to confirm Bay's find that bilateral visual discrimination defects may follow unilateral cerebral lesions. We canngt, however, find confirmation of his view that sugh defects play an appreciable part in the genesis the visual agnosias.

\section{Summary}

An investigation of visual sensory discriminat $\mathrm{n}$ in 30 cases of brain lesion is reported. The object was first to determine the incidence and magnitiole of sensory deficits in cases of cerebral lesion; apd secondly to assess their significance in relation to the visual agnosias. 
The cases fall into three groups on the basis of the presence of field defects and/or higher perceptual disorders. All patients were tested on a variety of visual discrimination tasks at representative points in the visual fields. Their results were evaluated with reference to the thresholds given by a large control group.

The presence of visual sensory deficits in perimetrically normal areas of the visual field, both ipsilateral and contralateral to the side of a unilateral lesion, was ascertained. The results did not, however, support the view that agnosic conditions are secondary to deficits of visual sensory discrimination.

I wish to thank the physicians and surgeons of the National Hospital, Queen Square, for permission to study the cases under their care; likewise Dr. W. Ritchie Russell, of the Radcliffe Infirmary, Oxford, and Dr. C. A. Pallis, of the Royal Infirmary, Cardiff, who generously allowed me to investigate their patients at the National Hospital. I am also indebted to Dr. Eliot Slater for special facilities. My especial gratitude is due to Prof. O. L. Zangwill for his constant encouragement, help, and advice.
The late Dr. L. C. Thomson, of the Institute of Ophthalmology, kindly gave me help in designing the optical system and made available certain optical equipment on loan. I am also extremely grateful to Mr. H. B. Morton who helped with the design and construction of parts of the electrical equipment (by kind permission of Dr. W. A. Cobb); to Mr. J. W. Whitfield for his valuable advice on statistical problems; to Mrs. E. Warrington for assistance with the analysis of the data; and to Dr. A. Elithorn for his assistance in preparing this paper.

\section{REFERENCES}

Bay, E. (1950). Agnosie und Funktionswandel. Springer, Berlin. (1953) Brain, 76, 515 .

Critchley, M. (1953). The Parietal Lobes. Arnold. London.

Ettlinger, G. (1955). Ph.D. Thesis submitted to London University. (1956). Quart. J. exper. Psychol. In the press.

Faust, C. (1951). Nervenarzi, 22, 176.

(1955). Die Zerebralen Herdstörungen bei Hinterhauptsverletzungen. Georg Thieme, Stuttgart.

Jaffe, R. (1955). A.M.A. Arch. Neurol. Psychiat., 73, 57.

Jung, R. (1951). Nervenarzt, 22, 192.

Jung, R. (1951) Nervenarzt, 22, 192. . A . 630.

McFie, J., Piercy, M. F., and Zangwill, O. L. (1950). Brain, 73, 167. Mallie, J., Piercy, M. F., and Zangwill, O. L. (1950). Brain, 73, 167. Pallis, C. A. (1955).

Russell, W. R. (1951). Proc. roy. Soc. Med., 44, 341.

Scheller, H. (1951). Nervenarzt, 22, 187. 